Führungsseminar für Oberärztinnen und Oberärzte Leitende Ärztinnen und Leitende Ärzte 2012-2013

\title{
Führungsprinzipien kennen und in der Praxis richtig einsetzen
}

Das Führungsseminar bietet Oberärztinnen und Oberärzten sowie Leitenden Ärztinnen und Leitenden Ärzten aller Fachrichtungen die Gelegenheit, die wesentlichen Führungsfragen zu reflektieren und relevante Führungstools für die Praxis kennenzulernen.

Die 4 Module $(4 \times 2$ Tage) werden von qualifizierten Experten vermittelt und beinhalten die wichtigsten führungsrelevanten Themen, z. B. «Die Rolle der Ärzte als Führungspersonen, Gesprächsführung in schwierigen Situationen, Qualifikation von Mit-

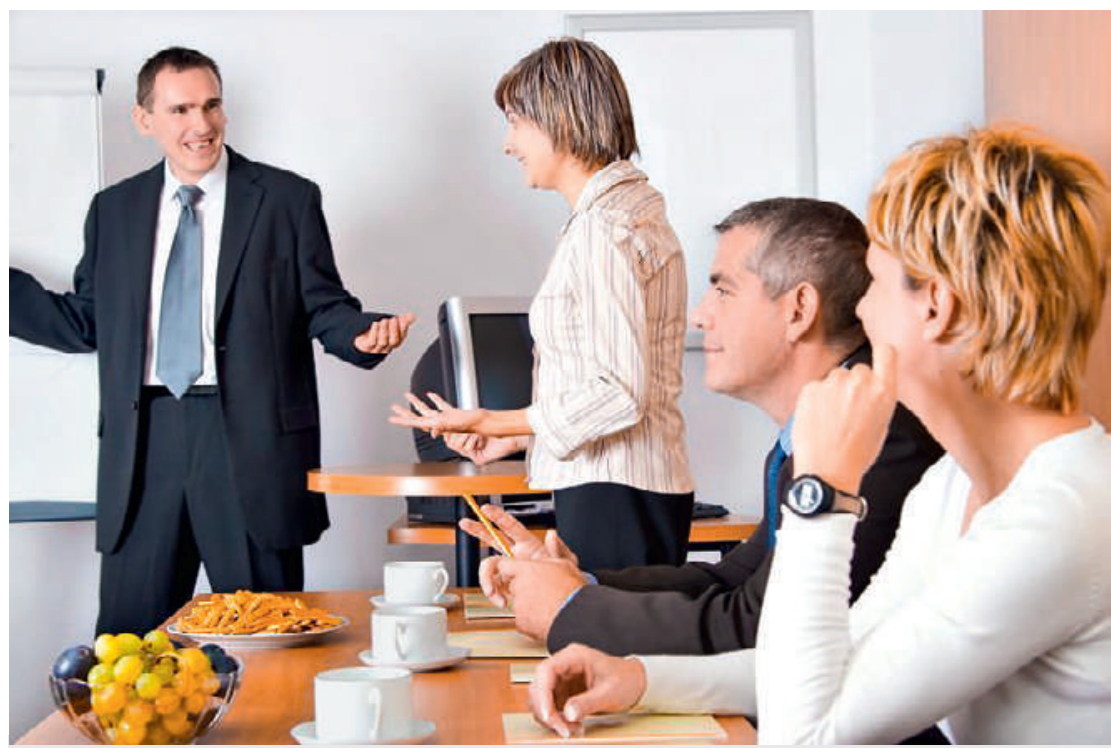

Die Seminare behandeln führungsrelevante Themen in 4 Modulen zu jeweils 2 Tagen. arbeitern, Konfliktmanagement, Teamentwicklung, Leiten von Sitzungen, Erkennen eigener Erfolgspotentiale, eigene Karriereplanung usw.» Der Kurs wird offiziell attestiert.

Das Führungsseminar richtet sich ausschliesslich an Oberärztinnen und Oberärzte, Leitende Ärztinnen und Leitende Ärzte aller Fachgebiete und wird vom SIWF-FMH für die Fortbildung mit 32 Credits anerkannt.

Daten

- 1 . und 2. November 2012

- 3. und 4. Dezember 2012

- 24. und 25. Januar 2013

- $\quad$ 14. und 15. März 2013

\section{Seminarort}

Kongress-Kursaal Bern

\section{Kurskosten}

5200 Franken für 8 Kurstage inkl. Mittagessen, Pausenverpflegung, Infrastruktur und Kursunterlagen.

\section{Anmeldeschluss}

15. September 2012

\section{Info und Anmeldungen}

biaggi-partner, führungsseminare

Kurssekretariat, Postfach 15, 3074 Muri

Tel. 0319517234

jean.biaggi[at]bluewin.ch

www.biaggi-partner.ch 